Please do not remove this page

RMIT

UNIVERSITY

\title{
Framing the private land conservation conversation: Strategic framing of the benefits of conservation participation could increase landholder engagement
}

Kusmanoff, Alexander; Hardy, Mathew; Fidler, Fiona; Maffey, Georgina; Raymond, Christopher; Reed, M; Fitzsimons, James

https://researchrepository.rmit.edu.au/esploro/outputs/9921860020501341/filesAndLinks?institution=61RMIT_INST\&index=null

Kusmanoff, A., Hardy, M., Fidler, F., Maffey, G., Raymond, C., Reed, M., Fitzsimons, J., \& Bekessy, S. (2016). Framing the private land conservation conversation: Strategic framing of the benefits of conservation participation could increase landholder engagement. Environmental Science and Policy, 61, 124-128. https://doi.org/10.1016/j.envsci.2016.03.016

Document Version: Accepted Manuscript

Published Version: https://doi.org/10.1016/j.envsci.2016.03.016

Repository homepage: https://researchrepository.rmit.edu.au (C) 2016 Elsevier Ltd.

Downloaded On 2023/04/26 22:48:58 +1000 
Thank you for downloading this document from the RMIT Research Repository.

The RMIT Research Repository is an open access database showcasing the research outputs of RMIT University researchers.

RMIT Research Repository: http://researchbank.rmit.edu.au/

\section{Citation:}

Kusmanoff, A, Hardy, M, Fidler, F, Maffey, G, Raymond, C, Reed, M, Fitzsimons, J and Bekessy, S 2016, 'Framing the private land conservation conversation: Strategic framing of the benefits of conservation participation could increase landholder engagement', Environmental Science and Policy, vol. 61, pp. 124-128.

See this record in the RMIT Research Repository at:

https://researchbank.rmit.edu.au/view/rmit:36474

Version: Accepted Manuscript

\section{Copyright Statement:}

(c) 2016 Elsevier Ltd.

\section{Link to Published Version:}

https://dx.doi.org/10.1016/j.envsci.2016.03.016 
Framing the Private Land Conservation Conversation: Strategic framing of the benefits of conservation participation could increase landholder engagement

Environmental Science \& Policy 61 (2016) 124-128

Alexander M. Kusmanoff*,a

Mathew J. Hardy, ${ }^{a}$

Fiona Fidler, ${ }^{a}$

Georgina Maffey,

Christopher Raymond ${ }^{c, d}$

M. S. Reed ${ }^{\mathrm{e}}$

James A. Fitzsimons,

Sarah Bekessy ${ }^{\mathrm{a}}$

*Corresponding author, email: alex.kusmanoff@rmit.edu.au

a School of Global Urban and Social Studies, RMIT University, GPO Box 2476, Melbourne VIC 3001 Australia

${ }^{\mathrm{b}}$ Aberdeen Centre for Environmental Sustainability (ACES), University of Aberdeen, $23 \mathrm{St}$. Machar Drive, Aberdeen AB24 3UU United Kingdom

${ }^{c}$ Environment and Sustainability Institute and Centre for Geography, Environment and Society, University of Exeter, Penryn, Cornwall, TR10 9FE

${ }^{\mathrm{d}}$ Stockholm Resilience Centre, Kräftriket 2B, Stockholm, Sweden

${ }^{e}$ Knowledge Exchange Research Centre of Excellence, Birmingham School of the Built Environment, Birmingham City University, Millennium Point, Curzon Street, Birmingham B4 7XG, United Kingdom

f The Nature Conservancy, Suite 2-01, 60 Leicester Street, Carlton VIC 3053, Australia.

${ }^{g}$ School of Life and Environmental Sciences, Deakin University, 221 Burwood Highway, Burwood VIC 3125, Australia

Keywords:

Framing, value orientation, biodiversity, conservation, private land conservation, marketbased instruments, communications, marketing 


\section{Abstract}

How conservation messages are framed will impact the success of our efforts to engage people in conservation action. This is highly relevant in the private land conservation (PLC) sector given the low participation rates of landholders. Using a case study of PLC schemes targeted at Australian landholders, we present the first systematic analysis of communication strategies used by organisations and government departments delivering those schemes to engage the public. We develop a novel approach for analysing the framing of conservation messages that codes the stated benefits of schemes according to value orientation. We categorised the benefits as flowing to either the landholder, to society, or to the environment, corresponding to the egoistic, altruistic and biospheric value orientations that have been shown to influence human behaviour. We find that messages are biased towards environmental benefits. Surprisingly, this is the case even for marketbased schemes that have the explicit objective of appealing to production-focussed landholders and those who are not already involved in conservation. The risk is that PLC schemes framed in this way will fail to engage more egoistically oriented landholders and are only likely to appeal to those likely to already be conservation-minded. By understanding the frame in which PLC benefits are communicated, we can begin to understand the types of people who may be engaged by these messages, and who may not be. Results suggest that the framing of the communications for many schemes could be broadened to appeal to a more diverse group (and thus ultimately to a larger group) of landholders.

\section{Introduction}

Private land conservation (PLC) has become increasingly common over the last twenty years as a means of implementing conservation action beyond the protected area network. Interna- tionally, PLC is implemented through a range of instruments including direct payments, tax incentives, cap and trade markets, voluntary markets and auctions and certification programs (Pascual and Perrings, 2007; Pirard, 2012; Yang et al., 2010). Despite widespread implementation, there has been mixed success in engaging rural landholders in conservation initiatives (e.g. Posthumus et al., 2010; Prager and Posthumus, 2010). Thinking strategically about how PLC messages to rural land-holders are framed could help increase engagement. To under- stand how messages are currently framed, we use an Australian case study to examine how PLC organisations currently promote the benefits of landholder participation. Our purpose here is to critically analyse the current information provided to this target group, and discuss alternative framings that may improve participation rates.

Communications strategies are important for informing land-holders about the purpose of a PLC program, how they can become involved, and the benefits of participation. Within this, there is much scope for promoting the benefits of any PLC scheme in a variety of frames. Previous studies indicate that a range of factors influence a landholder's decision to participate in PLC, for example, economic considerations, the adoptability of new 
practices, and the characteristics of landholders themselves have all been shown to be relevant (e.g. Ervin and Ervin, 1982; Lynne et al., 1988; Adesina and Zinnah, 1993; Negatu and Parikh, 1999; Greiner et al., 2009; Kuehne et al., 2013). We propose that social value orientation also plays an important role. Below we discuss what we mean by social value orientation, and explain why we have used this concept to critically analyse existing PLC messages.

\subsection{Background to value orientations: egoistic, social-altruistic and biospheric}

The value orientation concept builds on the homo economicus model of human behaviour that underpins traditional economics, recognising that narrow self-interest alone does not always guide human decision-making.1 The value orientation concept identifies two general approaches that people take when allocating resources in a social dilemma scenario, reflecting the differing degrees of self-interest that individuals show for others. People tend to either maximise their own payoff (i.e. exhibit narrow self-interest) or maximise the joint payoff (i.e. display altruism) (Gärling, 1999). People who display these alternative behaviours (i.e. 'value orientations') are referred to as non-co-operators (or pro-selves) and co-operators (or pro-socials), respectively. In the context of undertaking pro-environmental behaviours, a third value orientation, the 'biospheric' orientation in which an individual places primacy on the intrinsic value of the biosphere, is also relevant (De Groot and Steg $2007,2008)$. In this three value orientation framework, the pro-self value orientation is akin to the egoistic value orientation, while the pro-social value orientation is supplanted by both the social-altruistic and biospheric value orientations (De Groot and Steg, 2007). This framework describes how values inform individual choices; with egoistically oriented people tending to weigh the cost and benefits for them personally; social-altruistically oriented people tending to weigh the costs and benefits to other people; and biospherically oriented people tending to weigh the costs and benefits to the biosphere as a whole (De Groot and Steg, 2007). Egoistically oriented people are more likely to value such things as social power, wealth, authority, influence and ambition; social-altruisti-cally oriented individuals are more likely to value such things as equality, peace, social justice and helping others; and biospheri-cally oriented people are likely to value such things as unity with nature, respecting the Earth and pollution prevention (De Groot and Steg, 2007 following Schwartz,1992). In describing these value orientations it is convenient to talk in an idealised manner, implying that individuals act as if they were of either one orientation or another. In reality, value orientation is a continuous concept (Murphy et al., 2011) and may better be conceived as a spectrum upon which individuals exist, and may exhibit a combination of orientations that may vary across time. The way information is framed can influence environmentally significant behaviour (Opdam et al., 2015), and when information is framed to align with a person's values and beliefs, it has the greatest influence on behaviour (e.g. Hong and Zinkhan, 1995; Chernev, 2004; Florack and Scarabis, 2006; Ku et al., 2012). While individuals of a pro-social orientation (social-altruistic or biospheric) are more willing to engage in pro-environmental behaviour, this is not the only pathway by which an interest in 
and value for conservation may be evoked (Ives and Kendal, 2013). Communications about PLC provides an opportunity to present the case for participation not only to the biospheric and the social-altruistic, but also to the egoistic by emphasising those benefits that flow to the landholder or to society (or both) as a result of participation. As such, we could expect congruence between the benefits emphasised in PLC communications and engagement by land-holders with corresponding value orientations. For example, an egoistically oriented landholder may not be strongly engaged by the promise of conservation benefits, but may be motivated by wider benefits such as increased land productivity, a sense of achievement, the respect of peers, or greater opportunity for social interaction. By analysing the way PLC organisations frame the benefits of participation to landholders, we can gain insight into the breadth of the audience that are likely to be engaged. To ensure that communications are relevant and engaging to as broad a range of landholders as possible, the PLC sector ought to ensure that these three different kinds of benefits are included in their messaging. In this study, we examine the extent to which contemporary communications about PLC actively seek to engage individuals across the three value orientations. We make no assumptions about the dominant value orientation, if any, of rural landholders. In any case, a persons' orientation may change over time. Our motivation is to understand how messages are currently framed to inform approaches that may improve rates of participation in PLC schemes.

\section{Methods}

Communications pertaining to PLC schemes were analysed to identify the apparent benefits of each scheme. These were subsequently categorised as 'benefits to landholders', 'benefits to society' or 'benefits to conservation', corresponding to the value orientations outlined above. A sample of 20 Australian PLC schemes representing a variety of scheme types were chosen for content analysis (see Table 1 in the Supplementary material). This analysis involved identifying sentences on the PLC scheme's websites (accessed between December 2013 and March 2014) that described a benefit of participation, and coding these as either a benefit to landholders, a benefit to society, a benefit to conserva- tion or as any combination of these. The proportion of each type of benefit as a fraction of the total benefits described by each scheme was calculated and then averaged across all schemes to determine the relative proportion of each type of benefit described by the websites, across the Australian PLC sector. Websites were used as a convenient proxy for the wider communications by PLC schemes, noting that the Web is a useful source of information for farmers (Morrison et al., 2008), and that websites are increasingly the 'first point of contact' for many businesses and organisations (Flanna-gan, 2014; Musante et al., 2009). We employed a directed content analysis approach (Hsieh and Shannon, 2005) whereby our coding was based on the a priori identified benefit types derived from value orientation theory. All schemes were coded by a single coder, with double coding by a secondary coder 
to measure reliability. Double-coding was conducted on $27 \%$ of sentences (324 out of 1209 total sentences coded). The secondary coder agreed with the primary coder for $83 \%$ (140 of 168 sentences) of 'non-benefit' categorisations; $82.9 \%$ (63 of 76 sentences) of 'pro-self' (i.e. egocentric) categorisations; and $85.9 \%$ (85 of 99 sentences) of 'pro-social' (i.e. socialaltruistic plus biospheric) categorisations. The 'pro-social' sentences were then coded to discriminate between explicit conservation related benefits and other social benefits more broadly (or as both). The double-coding by the second coder here consisted of $20 \%$ (53 of 266 sentences) for which there was agreement with the primary coder of $81 \%$ (43 of 53 sentences). The initial count of landholder benefits included all apparent benefits, not all of which may rightly be considered as a 'true' benefit from the perspective of the egoistic value orientation. Many of these prima facie benefits are actually aimed at facilitating participation or removing barriers to participation, and do not offer a 'true' (egoistic) benefit in which a landholder would gain something from participation. For example, notional benefits such as minimal administration involved in participation, nil ongoing obligations, and free provision of additional fencing that may be required for participation may all be helpful in lowering the barriers to participation for landholders that already have an interest, yet offer no actual 'reward' for participation. Accordingly these types of benefits were identified and excluded, with $20 \%$ (59 out of 295) double coded, and both coders in agreement for $97 \%$ of instances ( 57 of 59 sentences). Rather than looking solely at the total count of the benefit sentences for each value orientation, it is more instructive to consider the relative proportions of all benefits for each scheme that are framed in each orientation. To calculate this, we first took the total number of benefit sentences of each value orientation, for each scheme separately, and calculated the relative proportions that these comprised of the total benefits described by each scheme. For example, if Scheme A had three benefit sentences coded 'egoistic', two coded 'social-altruistic' and four coded 'biospheric', then the relative proportion of each orientation for that scheme would be given by $3 / 9$ (i.e. 0.33 ), 2/9 (i.e. 0.22 ) and $4 / 9$ (i.e. 0.44 ), respectively. By averaging these proportions across all schemes, the average relative proportion of each benefit type (i.e. value orientation) was calculated.

\section{Results}

The total number of sentences that describe a benefit of PLC, when categorised simply as pro-self, pro-social, or both, are strongly dominated by pro-social benefits ( $64 \%$ of all benefits). If we consider the benefit sentences framed in terms of the three value orientations, and account for the relative proportion of each category as a component of the total benefits described by the website for each scheme, and averaged across all schemes, we see that biospheric (conservation) benefits make up the greatest proportion. On average (across all schemes) biospherically framed benefits accounted for $48 \%$ of communications related to the benefits of participation, while egoistically framed 
(landholder) benefits made up 33\% and social-altruistically framed benefits (to society) made up 19\% (Fig. 1). Five of the 20 schemes analysed were market-based schemes in which landholders competitively bid for funds to undertake specified conservation activities. These schemes are distinct from other PLC schemes in their reliance upon markets to find prospective participants, and are inherently designed to appeal to the more egoistic oriented landholder. Hence, we thought it would be interesting to see what the relative frequency of each benefit type was for these schemes, compared to the average for the sector. We note that this data should be used cautiously when drawing inferences about market-based schemes generally, as it is derived from a small sample of only five schemes. For the market-based schemes, on average (across all market-based schemes), biospherically framed (conservation) benefits made up $60 \%$ of communications that related to the benefits of participation, while egoistically framed (landholder) benefits made up $27 \%$ and social-altruistically framed benefits (to society) made up 13\% (Fig. 1).

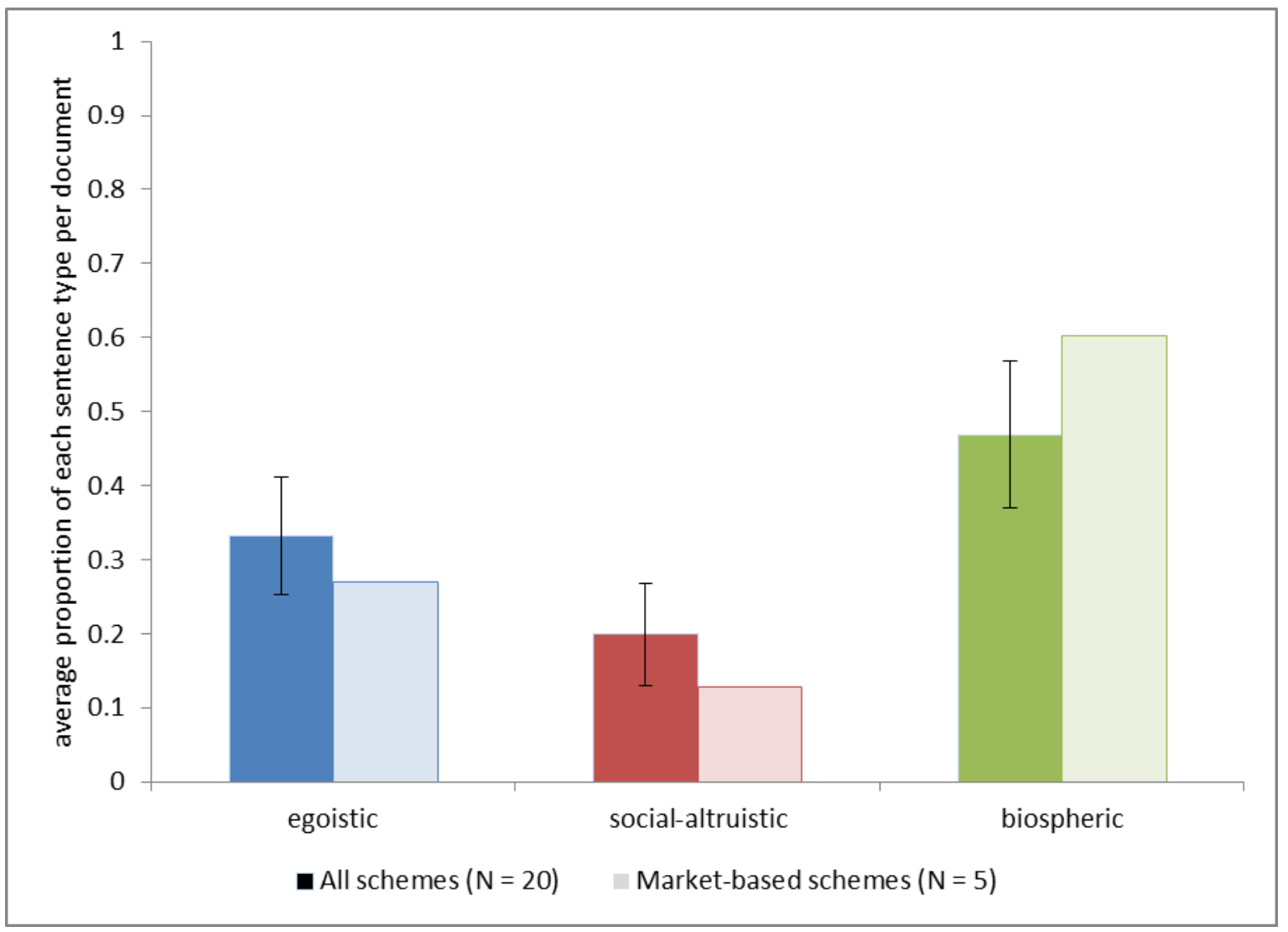

Fig. 1. Average proportions of benefits that are framed as egoistic, social-altruistic and biospheric benefits. Solid bars show the proportion across 20 Australian PLC schemes. Error bars are 95\% confidence intervals. Transparent bars show the proportion for 5 Australian market-based PLC schemes ( $\mathrm{n}$ insufficient for error bar calculation). 


\section{Discussion}

Of the three benefit types examined in this study, biospheric (conservation) related benefits are the most common type emphasised by PLC websites in Australia. The potential consequence of this bias is that landholders with a strong egoistic value orientation are less likely to be engaged by content on PLC program websites because the benefits have not been communicated in a way that aligns with their primary production interests (this would also include corporate farming entities). To ensure that egoistic landholders (and not only biospheric oriented landholders) are engaged by PLC program websites, new communication strategies need to be devised which link conservation interests to primary production and/or personal interests. The under-representation of egoistic (landholder) benefits in PLC communications may stem from a cautious approach to the use of financial incentives in conservation. In certain circumstances, financial incentives have the ability to crowd-out intrinsic motivations for conservation practices, and can be counterproductive to promoting conservation land management practices over the longer term (e.g. Frey and Jegen, 2001; Reeson, 2008). However, 'joining the dots' from conservation outcomes to public benefits can extend also to egoistic (landholder) benefits without the need for direct financial incentives. By explaining how certain conservation practices may aid or maintain productivity (Carvalheiro et al., 2011; Scherr and McNeely, 2008;) and allow increased diversification of income streams (e.g. from market-based schemes) that in turn provide some insurance against the threat of bushfire and drought, etc., conservation outcomes may be framed in a manner more receptive to the egoistic oriented landholder. In any case, there is evidence that financial incentives are important in recruiting production-based landholders to PLC schemes (Moon and Cocklin, 2011). The risk of such incentives crowding out intrinsic conservation motivations only exists where there is already an existing intrinsic conservation motivation (Stern, 2006), which may not necessarily be the case for egoistic landholders. If the underlying motivation for production-based landholders is to generate profit from the land there may be little competing conservation motivation to be crowded out. Rather, a financial incentive alone or in conjunction with other non-financial landholder benefits, may provide the motivation required to retire marginally profitable land from cropping or grazing in preference for conservation. Whilst the communications of some schemes did make some of these connections, they were used infrequently. Social-altruistic benefits (to society) were the least emphasised type of benefit, with more than twice as many biospheric (conservation) benefits emphasised. The social-altruistic benefits (to society) portrayed on the websites of PLC schemes tended to be less explicit and generally harder to define than either the biospheric (conservation) or egoistic (landholder) benefits. Given the relative subtlety with which the biospheric value orientation distinguishes itself from the social-altruistic value orientation, and generally only in instances of conflict between a pro-social outcome and a pro-environment outcome (De Groot and Steg 2007), this may be a missed opportunity to engage potentially receptive landholders. By explaining how conservation benefits will lead to, or could themselves be considered as public 
benefits, it may be possible to increase the emphasis of the social-altruistic benefits (to society).

\subsection{Market-based schemes}

The proportions of benefit types for the market-based schemes shows a similar distribution to that of the sector as a whole, although rather surprisingly, it is even more biospherically (conservation) framed, with such benefits making up a greater proportion of the communicated benefits (60\% compared to $48 \%$ ). This comes at the expense of socialaltruistic benefits (to society) ( $13 \%$ compared to $20 \%$ ), and egoistic (landholder) benefits ( $27 \%$ compared to $33 \%$ ). While we note the low sample size for this data, it arguably represents a lack of strategic framing, given that by providing monetary incentives to undertake conservation, market-based schemes seek in part to appeal to those landholders who would not otherwise be likely to engage in conservation behaviour without such financial incentives. As such, the significant focus on biospheric (conservation) benefits is arguably misaligned to the interests of this target landholder audience. Blackmore and Doole (2013) found that landholders who participate in market-based PLC are typically of a conservation mindset and are likely to engage in pro-conservation practices anyway. Our findings suggest that market-based schemes do not appear to strategically frame the benefits of participation in a way that would engage a broad range of landholders, particularly egoistic oriented landholders who are a key target audience.

\subsection{Framing failure}

This apparent failure of PLC scheme websites to make the case for conservation to those less biospherically oriented is consistent with criticisms that much of the environmental movement continues to preach only to the converted (e.g. Hope, 2014; Murray, 2012) and is not engaging the 'silent majority'. In discussing the importance of values in conservation messages, Ives and Kendal (2013, p. 71) point out that "many conservation messages fail to be as effective as they could be because the message is framed in a way that only a subset of people will find important" and thus communication strategies must be designed for the greatest effect. There is also a possibility that an emphasis on biospheric oriented (conservation) benefits may not be necessary in engaging landholders, given that consumers with positive attitudes toward the environment are equally receptive to weak as well as strong 'green' product claims (Tucker et al., 2012). It may be that biospheric oriented landholders are easily engaged by the conservation aspect of a PLC communication, even where the emphasis may not actually be on the biospheric (conservation) benefits. Meanwhile the over-emphasis of these benefits may fail to engage egoistic and socialaltruistic oriented landholders, however further research is needed. 


\subsection{Future directions for PLC communications}

This is the first study that we are aware of that has attempted to analyse PLC message content and further studies are required to show how pervasive this pattern is across the international PLC sector. Future research could adapt the novel approach used here to investigate the communications of specific categories of PLC schemes. Future investigations could examine the messages used by schemes within each type of PLC mechanism to understand the degree to which the framing of these benefits matches the value orientation of the landholders that the policy is designed to appeal to. This could provide further guidance for the strategic framing of PLC benefits and insight into the imbalance in the use of benefit types observed in this study. Future research could also consider the range of communications provided to landholders (website, printed, verbal, social media) and compared the similarities or differences between these framings. Finally, understanding how messages are currently framed is a good first step, but we also need research that tests the impact of alternatively framed PLC communications on landholders with different value orientations.

\section{Conclusions}

Here we have shown that there is a bias across the Australian PLC sector toward the framing of PLC participation benefits as conservation benefits. Increased use of egoistic and socialaltruistic frames in emphasising both landholder and social benefits of PLC may be advantageous in engaging a wider range (and greater number) of landholders. Appealing to a wider range of landholders is potentially key to improving participation rates. However, we caution that any promised benefits must be reasonably achievable by the landholder through their participation; over-promising and under-delivering could be a sure-fire means of permanently deterring the participation of many landholders. Furthermore, we need to investigate the potential for unintended feedback effects of messages matched to other value orientations, for example, the potential for motivation crowding out in egoistic (proself) messages. As a first step, we recommend PLC programs be aware of the value orientation frame implicit in their messages, and to consider whether this is a good match for their audience and their program's goal.

\section{Acknowledgements}

This research was conducted with funding support from the Australian Research Council Centre of Excellence for Environmental Decisions and the Australian Government's National Environmental Science Program (Threatened Species Recovery Hub). Bekessy and Fidler are funded by ARC Future Fellowships. 


\section{References}

Adesina, A. A., and M.M. Zinah 1993, 'Technology characteristics, farmers' perceptions and adoption decisions: a Tobit model application in Sierra Leone', Agricultural Economics vol. 9 no., pp. 297-311.

Blackmore, L., \& Doole, G. J. (2013). 'Drivers of landholder participation in tender programs for Australian biodiversity conservation', Environmental Science \& Policy, vol. 33 no., pp. 143-153.

Carvalheiro, L. G., Veldtman, R., Shenkute, A. G., Tesfay, G. B., Pirk, C. W. W., Donaldson, J. S., \& Nicolson, S. W. 2011, 'Natural and within-farmland biodiversity enhances crop productivity', Ecology letters, vol. 14 no. 3, pp. 251-259.

Chernev, A. 2004, 'Goal-attribute compatibility in consumer choice', Journal of Consumer Psychology, vol. 14 no. 1, pp. 141-150.

De Groot, J. I. and L. Steg 2007, 'Value Orientations and Environmental Beliefs in Five Countries Validity of an Instrument to Measure Egoistic, Altruistic and Biospheric Value Orientations', Journal of Cross-Cultural Psychology, vol. 38 no. 3, pp. 318-332.

De Groot, J. I. and L. Steg 2008, 'Value Orientations to Explain Beliefs Related to Environmental Significant Behavior How to Measure Egoistic, Altruistic, and Biospheric Value Orientations', Environment and Behavior, vol. 40 no. 3, pp. 330-354.

Ervin, C. A. and Ervin, D. E. 1982, 'Factors affecting the use of soil conservation practices: hypotheses, evidence, and policy implications', Land Economics vol. 58 no. 3, pp. 277-291.

Flannagan, R. (2014). "How important is your business website?" at: $<$ http://nuancedmedia.com/how-important-is-a-business-website/> Retrieved 22 October 2014.

Florack, A., \& Scarabis, M. 2006, 'How advertising claims affect brand preferences and category-brand associations: The role of regulatory fit', Psychology \& Marketing, vol. 23 no. 9, pp. 741-755.

Frey, B. S. a. J., R. 2001, 'Motivation crowding theory: a survey of empirical evidence', Journal of economic surveys, vol. 15 no. 5, pp. 589-611.

Gärling, T. 1999, 'Value priorities, social value orientations and cooperation in social dilemmas', British Journal of Social Psychology, vol. 38 no. 4, pp. 397-408.

Greiner, R., Patterson, L., \& Miller, O. 2009, 'Motivations, risk perceptions and adoption of conservation practices by farmers', Agricultural systems, vol. 99 no. 2, pp. 86-104. 
Hong, J. W., \& Zinkhan, G. M. (1995). Self-concept and advertising effectiveness: the influence of congruency, conspicuousness, and response mode. Psychology \& Marketing, 12(1), 53-77.

Hope, M. (2014). "Could rebranding environmentalism help tackle climate change?" $<$ http://www.carbonbrief.org/blog/2014/06/could-rebranding-environmentalism-helptackle-climate-change/> Retrieved 24 October 2014.

Hsieh, H. F., \& Shannon, S. E. 2005, 'Three approaches to qualitative content analysis', Qualitative Health Research, vol. 15 no. 9, pp. 1277-1288.

Ives, C. D., \& Kendal, D. 2013, 'Values and attitudes of the urban public towards peri-urban agricultural land', Land Use Policy, vol. 34 no., pp. 80-90.

Ku, H. H., Kuo, C. C., Wu, C. L., \& Wu, C. Y. 2012, 'Communicating Green Marketing Appeals Effectively: The Role of Consumers' Motivational Orientation to Promotion versus Prevention', Journal of Advertising, vol. 41 no. 4, pp. 41-50.

Kuehne, G., Llewellyn R., Pannell, D., Wilkinson, R., Dolling, P., Ouzman, J. (2013). ADOPT: the Adoption and Diffusion Outcome Prediction Tool (Public Release Version 1.0, June 2013) [Computer software] Adelaide SA; CSIRO. Available from www.csiro.au/ADOPT

Lynne, G. D., J.S. Shonkwiler, and L.R. Rola 1988, 'Attitudes and farmer conservation behavior. A merican Journal of Agricultural Economics, vol. 40 no. 12, pp. 12-19.

Moon, K., \& Cocklin, C. 2011, 'A Landholder-Based Approach to the Design of Private-Land Conservation Programs', Conservation Biology, vol. 25 no. 3, pp. 493-503.

Stern 2006

Morrison, M., Durante, J., Greig, J. \& Ward, J. (2008). Encouraging Participation in Market Based Instruments and Incentive Programs. Final Report prepared for Land and Water Australia.

Murphy, R. O., Ackermann, K. A., \& Handgraaf, M. J. 2011, 'Measuring social value orientation', Judgment and Decision Making, vol. 6 no. 8, pp. 771-781.

Murray, J. (2012). "Building a new environmentalism." $<$ http://www.businessgreen.com/bg/james-blog/2220056/building-a-newenvironmentalism> Retrieved 24 October 2014.

Negatu, W., and A. Parikh 1999, 'The impact of perception and other factors on the adoption of agricultural technology in the Moret and Jiru Woreda (district) of Ethiopia', Agricultural Economics, vol. 21 no., pp. 201-216. 
Opdam, P., Coninx, I., Dewulf, A., Steingröver, E., Vos, C., \& van der Wal, M. 2015, 'Framing ecosystem services: Affecting behaviour of actors in collaborative landscape planning?', Land Use Policy, vol. 46, pp. 223 - 231.

Pascual, U., Perrings, C. 2007, 'Developing incentives and economic mechanisms for in situ biodiversity conservation in agricultural landscapes', Agriculture, Ecosystems \& Environment, vol. 121 , pp. $256-268$.

Persky, J., 1995. Retrospectives: the ethology of homo economicus. J. Econ. Perspect. 9, 221-231.

Pirard, R., 2012.2012, 'Market-based instruments for biodiversity and ecosystem services: a lexicon', Environmental Science \& Policy, vol. 19, pp. 59-68.

Posthumus, H. G., C. and Ruben, R. 2010. 2010, 'From participation to adoption: comparing the effectiveness of soil conservation programs in the Peruvian Andes', Land Economics, vol. 86 no. 4 , pp. 645-667.

Prager, K. and Posthumus, H. (2010). Socio-economic factors influencing farmers' adoption of soil conservation practices in Europe. Human Dimensions of Soil and Water Conservation: A Global Perspective. T. Napier. USA, Nova Science Publishers: 203-223.

Reeson, A. (2008). Institutions, motivations and public goods: theory, evidence and implications for environmental policy. Socio-economics and the environment in discussion CSIRO working paper series. Canberra.

Scherr, S. J., and McNeely, Jeffrey A. 2008, 'Biodiversity conservation and agricultural sustainability: towards a new paradigm of 'ecoagriculture'landscapes', Philosophical Transactions of the Royal Society B: Biological Sciences, vol. 363 no. 1491, pp. 477-494.

Schwartz, S. H. (1992). Universals in the content and structure of values: Theoretical advances and empirical tests in 20 countries. Advances in experimental social psychology. M. Zanna. Orlando Florida, Academic Press.

Stern, S. 2006, 'Encouraging Conservation on Private Lands: A Behavioral Analysis of Financial Incentives', Ariz. L. Rev, vol. 48 no., pp. 541.

Tucker, E. M., Rifon, N. J., Lee, E. M., \& Reece, B. B. 2012, 'Consumer Receptivity to Green Ads: A Test of Green Claim Types and the Role of Individual Consumer Characteristics for Green Ad Response', Journal of Advertising, vol. 41 no. 4, pp. 9-23.

Yang, W. H., Bryan, B.A., MacDonald, D.H., Ward, J.R., Wells, G., Crossman, N.D., Connor, J.D. 2010, 'A conservation industry for sustaining natural capital and ecosystem services in agricultural landscapes', Ecological Economics, vol. 69 no. 680-68. 